\title{
Eugenia: uma ciência estigmatizada
}

\author{
Eugenics: a stigmatized science
}

\author{
Gerson Pietta \\ Doutorando, Programa de Pós-graduação em História/Universidade Federal do Paraná. \\ gersonpietta@gmail.com
}

Francesco Cassata

Eugenetica senza tabú Usi e abusi di un concetto

\section{(293.}

L'uso del concetto di «eugenetica» nel dibattito pubblico non è che un guscio vuoto. La sua adozione non chiama in causa un preciso oggetto storico, ma semplicemente proietta i nostri orientamenti, i nostri obiettivi e le nostre paure.

CASSATA, Francesco. Eugenetica senza tabú: usi e abusi di un concetto. Turim: Giulio Einaudi. 2015. 130p.
$\mathrm{F}$ oi lançado em 2015, pela editora Giulio Einaudi, o livro Eugenetica senza tabú: usi e abusi di un concetto, de Francesco Cassata, professor do Departamento de Filosofia, História e Geografia da Universidade de Gênova. Cassata tem trajetória significativa no que diz respeito a pesquisas e produções acerca de eugenia, raça e genética no contexto italiano. O livro é organizado em três capítulos: o primeiro discute o processo de nazificação da eugenia e de banalização do nazismo; o segundo propõe um modelo de descontinuidade no que se refere a um tabu negativo quanto aos usos da eugenia no pós-1945; o terceiro capítulo discute a inadequação heurística do conceito de "retorno à eugenia".

Eugenetica senza tabú analisa como se produziu no debate público italiano um aparato discursivo hostil em relação à biomedicina e à genética contemporâneas, produzido, em tese, a partir do caráter negativo que o termo "eugenia" adquiriu após a experiência

nazista. A eugenia passou a ser vista como sinônimo de pseudociência reacionária, sexista, racista e antissemita, além de fonte de violência e discriminação, interpretada em todas as especificidades históricas, entre elas a italiana (p.4). Tal interpretação deixa de lado definições conceituais como as de Daniel J. Kevles (1985), Mark Adams (1990) e Nancy Stepan (2005), pioneiros no estudo da história da eugenia, que distinguiram variantes da ciência eugênica a partir de ligações com diferentes contextos nacionais ou regionais. Essa historiografia, à qual a obra de Cassata se associa, reforça a essência não monolítica da eugenia e seu caráter multiforme, nas variantes políticas, sociais e culturais.

Para desconstruir a visão estigmatizada do termo "eugenia" no debate público, Cassata cita como exemplo seu uso pelo movimento sionista em prol do novo hebreu ou mesmo seu caráter modernizante e tecnocrático que atraiu o interesse de grupos distintos como os novos liberais, o fabianismo britânico, as sociais-democracias alemã e escandinava, o progressismo americano, o radicalismo e o comunismo francês. Além da eugenia bolchevista e reformista, chama atenção seu uso por grupos feministas, demonstrando as várias orientações 
ideológicas e políticas possíveis. Em contraposição aos usos anglo-saxões e nórdicos, como as esterilizações e os exames pré-nupciais, o autor enumera os usos do conceito no mundo latino: a assistência materna e infantil, a medicina social preventiva, o natalismo demográfico, o controle biotipológico e endocrinológico (p.7).

O interesse do autor não é produzir uma história sintética da eugenia, mas refletir sobre o "uso público do conceito, seus tropos, suas contradições e suas funções" (p.7). Segundo Cassata, no debate público italiano houve um movimento de nazificação do conceito de "eugenia" a partir do processo de Nuremberg, ocorrido entre 1946 e 1947, e da conclusiva relação entre genética médica e os crimes de Auschwitz. O autor propõe uma descontinuidade em relação ao tabu da eugenia, que, para ele, não ocorreu com o fim da Segunda Guerra Mundial, e sim no final dos anos 1960 e início dos anos 1970. Ou seja, até a segunda datação, na Itália, a eugenia possuía significado positivo, ligado aos aconselhamentos genéticos na esfera da saúde pública.

O autor faz crítica à forma como o reductio ad Hitlerum - expressão cunhada pelo filósofo alemão Leo Strauss - opera duplamente nos autores André Pichot e Rinhard Weikart, seja pela redução do termo "eugenia" ao contexto nazista e sua ligação ao racismo e ao antissemitismo, seja pela banalização e descontextualização do conceito, interpretado como pseudociência e privado de sua dimensão racional. Há também a reflexão em torno da representação construída no debate público, em que os eugenistas italianos são tidos como aceitáveis, e os eugenistas alemães como reprováveis. Ou seja, em contraposição à eugenia nórdica coercitiva, criou-se a ideia de uma eugenia latina mais branda: católica, sem excessos, moderada e humana, com práticas ligadas à hidroterapia, helioterapia, eletroterapia, aos banhos termais, à biotipologia ortogênica e à endocrinologia de Nicola Pende (p.26). O autor reforça que foi excluída do debate público a campanha racista e antissemita de Pende, que a defendeu em meados de 1930.

Cassata afirma que o uso obsessivo da analogia nazificante da eugenia produziu uma contra-argumentação falaciosa, apontando que o fim da Segunda Guerra Mundial, a descoberta de Auschwitz e o processo dos médicos de Nuremberg teriam inaugurado uma nova era dominada pela recusa de múltiplos preconceitos, seja de raça, de classe ou de gênero, e pela afirmação de um consentimento livre e esclarecido na esfera da reprodução. Utilizando-se de interrogações de Carlo Alberto Defanti, o autor reflete: seria correto falar em colapso do eugenismo? De um lado, menciona o autor, houve a emergência de uma genética, entre 1920 e 1930, que teve como modelo uma eugenia reformadora, solidamente estabelecida sobre a matemática mendeliana e politicamente hostil ao racismo e ao classicismo da eugenia ortodoxa. Por outro lado, a eugenia ortodoxa, coercitiva e violenta, prosseguiu até a década de 1960, como no caso da Carolina do Norte. ${ }^{1}$ Fica evidente, para Cassata, que, depois da Segunda Guerra Mundial, a eugenia recontextualizou-se em um processo histórico gradual e complexo, presa a ambiguidades e contradições.

No trabalho de Casssata, além da emergência do que é conhecido como "aconselhamento genético" (genetic counseling), o desenvolvimento de controle médico de duas patologias genéticas é considerado historicamente relevante para compreender a transformação do conceito de "eugenia": a fenilcetonúria e a talassemia. Isso porque a forma de pensar maneiras de lidar com as patologias havia se alterado: de uma forma ortodoxa e coercitiva de eugenia - considerada insensata moral e cientificamente - para uma forma de eugenia mais sensível e 
humana. ${ }^{2}$ A partir da pesquisa de Lionel Penrose, aponta Cassata, foi possível uma mudança substancial da eugenia para a genética humana na abordagem da fenilcetonúria, também ocorrendo uma mudança semântica, posto que era sugerida uma solução preventiva para uma doença mental. Na esteira dessa interpretação, o autor investiga a talassemia. ${ }^{3}$ A pesquisa sobre a doença, realizada entre 1946 e 1961 na Universidade de Roma, foi financiada pela Fundação Rockefeller. Foram examinadas, em todo o território italiano, mais de trinta mil pessoas. A investigação concluiu que a doença era hereditária, e, assim sendo, com o emprego de testes de triagem, seria possível fazer uma campanha para prevenir a união matrimonial entre os portadores da doença, e mesmo alcançar a eliminação da enfermidade. ${ }^{4}$ A partir dessas mudanças no campo da genética humana, emerge a expressão genetic counseling, cunhada por Sheldon Reed em 1947. Com esse novo olhar, alterou-se o termo "paciente" para "cliente", além de se praticar o ensino da autonomia e da não coerção. Esses casos são sinais e evidências de que Nuremberg não representou censura nas pesquisas eugênicas, conforme apontou Cassata.

Cassata trabalha com um terceiro uso público do conceito de "eugenia", ao referir-se a uma categoria monolítica denominada "retorno à eugenia" (p.48), que desconsidera a complexa dinâmica de desenvolvimento da engenharia genética e da medicina individualizada do século XXI. O autor traz à tona e relaciona dois eventos: a sentença do caso Buck versus Bell, de 1927, no qual estava em julgamento a esterilização de uma família dita degenerada; e uma sentença de 2013, o caso Myriad, no qual a empresa Myriad Genetic pretendia patentear produtos da natureza - genes humanos isolados. A pretensão do autor ao relacionar os dois casos foi refletir sobre processos jurídicos envolvendo o público e o privado.

A perspectiva utilizada por Cassata para refletir sobre como ocorreram os debates em torno da eugenia, sobretudo a partir da opinião pública italiana e em três momentos diferentes, é relevante porque expõe os equívocos nas interpretações que são divulgadas popularmente e aceitas pelo público não acadêmico. Tal abordagem instiga também trabalhos para a compreensão da eugenia no contexto público, nacional e internacional, não só na Europa mas também na América Latina, possibilitando alargar a discussão sobre o conceito de "eugenia latina", fortemente enfatizado na historiografia recente.

\section{NOTAS}

${ }^{1} \mathrm{O}$ estado da Carolina do Norte, nos EUA, continuou a autorizar esterilizações eugênicas sem consenso legal até o fim dos anos 1960, sobretudo em mulheres afro-americanas em condição de extrema pobreza.

2 A fenilcetonúria, ou PKU, é uma grave anomalia do metabolismo, que se transmite como caractere autossômico recessivo, causando lesão cerebral irreversível.

${ }^{3}$ Uma anomalia no sangue, de caráter hereditário, que era frequente em regiões da Itália mediterrânea e insular e nos anos 1920 estava ligada à etiologia de uma grave enfermidade conhecida como a doença de Cooley (na nomenclatura atual, denominada talassemia maior, ou anemia mediterrânea).

${ }^{4}$ Caso interessante ocorreu em outubro de 1949 , durante o $50^{\circ}$ Congresso da Sociedade Italiana de Medicina Interna, no qual os pesquisadores apresentaram os resultados da pesquisa. Na ocasião, o hematólogo Giovani Di Guglielmo propôs a esterilização de todos os portadores da doença. Já o antropólogo Sergio Sergi invocava um exame de sangue obrigatório para todos nas áreas afetadas (p.39). 


\section{REFERÊNCIAS}

ADAMS, Mark B.

Eugenics in the history of science. In: Adams, Mark B. (Org.). The Wellborn science: eugenics in Germany, France, Brazil and Russia. New York: Oxford University Press. p.3-7. 1990.

KEVLES, Daniel.

In the name of eugenics: genetics and the uses of human heredity. Berkeley: University of California Press. 1985.
STEPAN, Nancy Leys.

A hora da eugenia: raça, gênero e nação na América Latina. Rio de Janeiro: Editora Fiocruz. 2005.

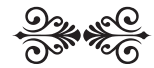

